This item was submitted to Loughborough's Research Repository by the author.

Items in Figshare are protected by copyright, with all rights reserved, unless otherwise indicated.

\title{
Fatigue of cracked high performance fiber reinforced concrete subjected to bending
}

PLEASE CITE THE PUBLISHED VERSION

https://doi.org/10.1016/j.conbuildmat.2019.06.038

PUBLISHER

(C) Elsevier

VERSION

AM (Accepted Manuscript)

\section{PUBLISHER STATEMENT}

This paper was accepted for publication in the journal Construction and Building Materials and the definitive published version is available at https://doi.org/10.1016/j.conbuildmat.2019.06.038.

LICENCE

CC BY-NC-ND 4.0

\section{REPOSITORY RECORD}

Carlesso, Debora M., Albert De la Fuente, and Sergio Pialarissi-Cavalaro. 2019. "Fatigue of Cracked High Performance Fiber Reinforced Concrete Subjected to Bending". Loughborough University.

https://hdl.handle.net/2134/38187. 
Fatigue of cracked high performance fiber reinforced concrete subjected to bending

Debora Martinello Carlesso $^{\text {a* }}$ (debcarlesso@gmail.com), Albert de la Fuente Antequera ${ }^{a}$ (albert.de.la.fuente@ upc.edu), Sergio Henrique Pialarissi Cavalaro ${ }^{\mathrm{b}}$ (S.Cavalaro@lboro.ac.uk)

a: Polytechnic University of Catalonia - BarcelonaTECH, Barcelona, Spain

b: Loughborough University, Loughborough, United Kingdom

*: Corresponding author

\begin{abstract}
High performance fiber reinforced concrete (HPFRC) is recognized as suitable material for structural applications. The number of national codes that have approved it is an evidence. Structures where HPFRC is generally used can be subjected to fatigue loads and are expected to resist millions of cycles during their service life. Cyclic loads affect significantly the characteristics of materials and can cause fatigue failures. The most demanded cross-sections being cracked under tensile stresses due to direct loads or imposed deformations. Commonly, publications report fatigue behavior of concrete under compression and are valid for uncracked sections. Imprecision in fatigue prescriptions are reflected through formulation of models that contemplate a probabilistic approach, or introduction of high safety coefficients within construction codes. The aim of the present research is to perform a structural design oriented analysis on the behavior of pre-cracked HPFRC subjected to flexural fatigue loads. Seven load levels were applied by means of three-point bending tests, considering an initial crack width accepted in the service limit state. Results showed that the monotonic load-crack opening displacement curve might be used as deformation failure criterion for HPFRC under flexural fatigue loading. The conducted probabilistic approach allows predicting the fatigue strength of HPFRC cracked sections.
\end{abstract}

Keywords

Fatigue; high performance fiber reinforced concrete; cracked section; steel microfibers

\title{
1. Introduction
}

Fiber reinforced concrete (FRC) and high performance fiber reinforced concrete (HPFRC) are recognized as suitable materials for structural applications such as tunnel linings [1], pavements [2], highway or bridge decks overlays [3,4], wind energy towers [5,6], offshore structures $[7,8]$ seismic resistant structures $[9,10]$ and for the repair of old structures and infrastructure facilities [11]. These structures can be subjected to cyclic loads and these are expected to resist millions of cycles during their service life. The most demanded cross-sections of these structures being cracked under tensile stresses due direct loads or imposed deformations (e.g., thermal-hygrometric induced stresses, differential settlements).

Cyclic loads affect significantly the characteristics of materials (strength, stiffness, toughness, durability, etc.) even under service loads [12,13] and could lead to fatigue failures. Recommendations, technical reports and guidelines on fatigue in (ultra) high performance concrete are available, such as the State-of-art report from the American Federal Highway Administration [14], the Japan Recommendations for Design and Construction of High Performance Fiber Reinforced Cement Composites [15], the fib Model Code 2010 [16], which covers concrete up to $120 \mathrm{MPa}$, the DNV GL standard [17], the French standards [18,19], and the draft of the German guideline [20]. Most of these publications report the fatigue behavior of concrete under compression, just a few take into consideration the flexural tensile response. 
Nevertheless, those reports dealing with flexural tensile fatigue are valid for uncracked sections while only a few give recommendations for post-cracking fatigue response.

Traditionally, the fatigue of FRC has been analyzed through S-N curves, which correlate the applied fatigue load and the fatigue life, this allowing to predict its fatigue performance. Numerous researches have been conducted to investigate the influence of different fatigue parameters such as stress level, stress ratio, loading frequency, and material properties, but just a few have done fatigue tests on pre-cracked concrete specimens. Table 1 shows the investigations in fatigue with steel fiber reinforced concrete.

Table 1 - Investigation in fatigue with steel fiber reinforced concrete

\begin{tabular}{ccccc}
\hline \multirow{2}{*}{ Reference } & \multicolumn{2}{c}{ Fatigue evaluation approach } & \multirow{2}{*}{ Pre-cracked cross section } \\
\cline { 2 - 4 } & Compression & Tension & Flexural & \\
\hline$[21-23]$ & $\mathrm{x}$ & & & \\
\hline$[24]$ & & $\mathrm{x}$ & & $\mathrm{x}$ \\
\hline$[24-27]$ & $\mathrm{x}$ & $\mathrm{x}$ & $\mathrm{x}$ \\
\hline$[12,13,36-38,28-35]$ & & $\mathrm{x}$ & \\
\hline$[9,39-41]$ & & & &
\end{tabular}

Surrounding conditions and inherent quality of FRC element itself produce scatter of test results. The main sources of scatter can be classified into three groups [42]: the intrinsic scatter of the material, caused by random distribution and orientation of the fibers; the process of production of the samples; variations associated to the precision of the equipment and set-up used in the test. This variation becomes more pronounced when interpreting fatigue results, once the phenomenon itself is known for having considerable scatter [16,43]. This characteristic leads to either the formulation of models that take into account logical basis for analyzing design uncertainties to ensure the adequate evaluation of failure probability [44]; or introduce high safety coefficients to assess the imprecision in fatigue prescriptions within construction codes [45].

Since cyclic load in cracked cross sections can be a governing design parameter, this must be investigated in terms of both applied fatigue load and respective number of cycles and of damage accumulation process since crack widths and loading bearing capacity evolution until failure are affected. Validation of the structural safety should consider values of crack opening correspondent to the expected fatigue life of the element during its service life [41].

The objective of this research is to perform a structural design oriented analysis on the behavior of pre-cracked HPFRC sections subjected to flexural fatigue loads. For this purpose, an extensive experimental program together with theoretical studies on the cyclic and static behavior were carried out. Results showed that the monotonic load-CMOD curves might be used as a deformation failure criterion for HPFRC under flexural fatigue loading. The conducted probabilistic approach allows predicting the fatigue strength of HPFRC cracked sections. This research contributes with a database containing representative flexural fatigue test results of HPFRC that can be used for generating specific models for fatigue consideration in structures to be introduced in future codes.

\section{Literature review}

Chanvillard et al. [39] investigated the three-point bending fatigue tests on an ultra-high performance fiber reinforced concrete (UHPFRC), the pre-crack width being $0.3 \mathrm{~mm}$. Fatigue test was load-controlled, between $10 \%$ and $90 \%$ of the first crack load, which was approximately half of the ultimate flexural strength. Fatigue test was stopped at 1,200,000 cycles. No specimen failed under these conditions and little damage was observed. After fatigue testing, the specimens were subjected to static flexural load and there was no influence of 
preceding cyclic loading process on the ultimate strength of the specimens. An endurance limit at 1,000,000 cycles was estimated to be at about $54 \%$ of the elastic limit strength.

Naaman and Hammoud [40] carried out an experimental program on fatigue of HPFRC. Three different target load ranges were applied: maximum load of $70 \%, 80 \%, 90 \%$ of the ultimate flexural capacity, and minimum load was kept constant of $10 \%$. The ultimate flexural capacity was obtained from the corresponding static test made with control specimens. The beams were pre-cracked prior cyclic loading with two to three visible cracks. The relation between maximum fatigue stress and number of cycles to failure suggested a fatigue endurance limit of 2,000,000 cycles of the order of $65 \%$ of ultimate load. The specimens that resisted the dynamic load were subjected to a static bending test up to failure. Results showed that preceding cyclic load may lead to an improvement in post-fatigue strength.

Germano et al. [9] studied the fatigue behavior of FRC on notched beams under three point bending test. It was adopted two volume fractions of fibers $(0.5$ and $1.0 \%)$ and three fatigue load levels: load amplitude was kept constant (50\%) and cyclic load varied between 15 $-65 \%, 25-75 \%$ and $35-85 \%$ of the maximum applied load. The pre-crack was done considering a drop of 5\% of the referred beam peak load. Dynamic cycles were imposed until the CMOD reached the equivalent width of the static curve bound failure. After that, it was monotonically loaded. Results showed that the fatigue deformations at failure match the monotonic stress-strain curves and these, in consequence, can be used to express fatigue failure. Crack opening range and crack opening increment per cycle are the two parameters that govern the fatigue life.

González et al. [41] analyzed the residual tensile strength of steel fiber-reinforced concretes following cyclic flexural loading. Pre-crack was considered effective either if the applied load fell to $90 \%$ of the maximum load applied during the test or if vertical deflection of the specimen was over $0.125 \mathrm{~mm}$. The maximum applied stress was $65 \%$ of its post-cracking flexural tensile strength, obtained in the earlier pre-cracking tests and the minimum applied stress was $5 \%$. Weibull fitting was used to obtain the characteristic fatigue life, considered to be 2,260 cycles. Results showed that cyclic loads cause a progressive reduction in the stiffness of the specimens. The reduction is attributable to the cracking in the fiber-matrix interface, causing a reduction of fiber-concrete bond, which results in a reduction of the residual strength.

The limited studies on flexural fatigue on pre-cracked concrete reveals that a broader understanding of the overall behavior is necessary. Applying percentages of actual resisted load of each specimen instead of using mean results from flexural test, can help reducing the scatter, providing concise information. Wider ranges of applied cyclic load, controlled pre-crack widths, tests up to 2,000,000 cycles, post-fatigue behavior and probabilistic approach should be taken into consideration aiming at generating design-oriented constitutive models.

\section{Experimental program}

An experimental investigation was carried out on the post-cracking flexural fatigue behavior of high performance concrete reinforced with steel microfibers. It was characterized the cyclic behavior and the fatigue life of the material. It was evaluated properties in static conditions and the results compared with dynamic loads in order to detect if the variations observed in the fatigue tests could be identified in the static behavior.

\subsection{Mix design, casting and curing procedures}

HPFRC specimens were cast with Portland cement CEM I-52R, a rounded shape fine siliceous aggregate and a polycarboxylate based superplasticizer. It was utilized an ultrafine calcium carbonate and a water-based amorphous nanosilica $\left(\right.$ nano- $\left.\mathrm{SiO}_{2}\right)$ dispersion to achieve 
optimum packing, flowability and lower porosity. The effective water/cement ratio was 0.20 . Table 2 shows the concrete mix.

Table 2 - Composition of HPFRC

\begin{tabular}{cc}
\hline Materials & Mix proportion $\left(\mathrm{kg} / \mathrm{m}^{3}\right)$ \\
\hline Cement content & 909 \\
\hline Water & 83 \\
\hline Silica sand $(0.3-0.7 \mathrm{~mm})$ & 1,103 \\
\hline Calcium carbonate & 100 \\
\hline Nano-SiO & 65 \\
\hline Superplasticizer & 64 \\
\hline Microfibers & 150 \\
\hline
\end{tabular}

The steel microfiber used in HPFRC had length $\left(\mathrm{L}_{\mathrm{f}}\right)$ of $13 \mathrm{~mm}$ and diameter $\left(\Phi_{\mathrm{f}}\right)$ of 0.16 $\mathrm{mm}$, leading to an aspect ratio $\left(\mathrm{L}_{\mathrm{f}} / \Phi_{\mathrm{f}}\right)$ of 82 ; the tensile strength and the elastic modulus were $3,000 \mathrm{MPa}$ and $200 \mathrm{GPa}$, respectively. The volume fraction of microfibers corresponds to, approximately, $2.0 \%$ ( $150 \mathrm{~kg}$ of fibers per $\mathrm{m}^{3}$ of concrete). The mixture was chosen based on previous tests and responds to applications with high structural responsibility, mainly oriented to precast concrete elements for wind towers and rail-track sleepers.

Seven cylinders $\left(\Phi_{\text {cyl }}=100 \mathrm{~mm} ; \mathrm{h}_{\mathrm{cyl}}=200 \mathrm{~mm}\right)$ were cast for compressive strength and elastic modulus tests. Twenty-four beams $\left(75 \times 75 \times 275 \mathrm{~mm}^{3}\right)$ were prepared for static flexural strength and fatigue tests. The beam size was chosen pondering a reduction of material and ease of handling. After casting, the specimens were left to cure at room temperature for 24 hours, covered with a thin plastic sheet; then, demolded and stored in a humid chamber (approximately $20{ }^{\circ} \mathrm{C}, 95 \%-100 \%$ relative humidity) until the day of the test. Beam specimens were notched at midspan. Static tests were performed at 28 days. Fatigue tests were performed between 30 to 120 days after cast. The flexural strength evolution in time for materials with low water/cement ratio is considered negligible within this timeframe [32].

\subsection{Experimental procedures}

\subsubsection{Control tests}

Four cylinders were tested under compressive strength tests in accordance to Standard UNE-EN 12390-3:2009, under a constant rate of loading of $0.5 \mathrm{MPa} / \mathrm{s}$. Three cylinders were tested under elastic modulus following the UNE-EN 12390-13:2014, with loading cycles up to $30 \%$ of the mean compressive strength value and measuring the corresponding strain by LVDT transducers. Both tests were performed in a universal compression testing machine IBERTEST MEH-3000 with maximum load capacity of 3,000 kN.

Static monotonic three-point bending test (3PBT) were carried out on three notched beams following the procedures of Standard UNE-EN 14651:2007 in an INSTRON hydraulic servo-controlled testing machine with MTS control. The capacity of the machine is $200 \mathrm{kN}$ for static tests and $100 \mathrm{kN}$ for dynamic tests. The crack mouth opening displacement (CMOD) was measured through a clip gauge placed on the notch at midspan. Figure 1 shows the test set-up. 


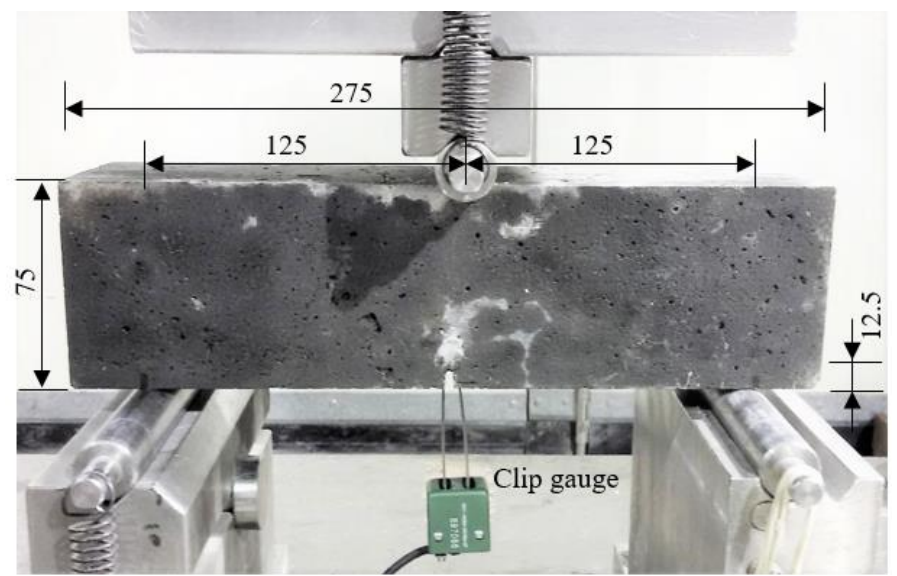

Figure 1 - Three-point bending test set-up in 75 × 75 x $275 \mathrm{~mm}$ beam (single column)

\subsubsection{Dynamic tests}

Twenty-one beams were tested under fatigue loading. Dynamic tests adopted the same configuration of the static 3PBT. Fatigue tests were load-controlled with the purpose of monitoring the crack opening in the beam and its fatigue life. As an attempt to reduce the scatter, it was performed a method of individual fatigue life evaluation of each beam. This experimental procedure also allowed to determine the contribution of the fibers in a cracked cross section.

First, a constant deformation rate $(0.05 \mathrm{~mm} / \mathrm{min})$ was imposed up to a CMOD of 0.5 $\mathrm{mm}$ (considered as service limit value according to fib Model Code 2010 [16]); therefore, the fatigue assessment would consider the fiber strength and the fiber-matrix interface within a precracked cross section. Then, to each specimen, the corresponding load to a crack opening of 0.5 $\mathrm{mm}\left(\mathrm{f}_{\mathrm{R}, 1}\right)$ was obtained in the first loading stage and set as maximum load $\left(\mathrm{P}_{0.5 \mathrm{~mm}}\right)$. Once $\mathrm{P}_{0.5 \mathrm{~mm}}$ is known, percentages of $\mathrm{P}_{0.5 \mathrm{~mm}}$ were chosen as cycle's upper limit of applied load $\left(\mathrm{P}_{\text {upp }}\right)$. The lower load ( $\left.\mathrm{P}_{\text {low }}\right)$ was determined as a function of the load amplitude which was kept constant $\left(\mathrm{R}=\mathrm{P}_{\text {low }} / \mathrm{P}_{\text {upp }}=0.3\right)$. It was tested three to four specimens of each percentage of $\mathrm{P}_{0.5 \mathrm{~mm}}$ (load level S) being $0.65,0.70,0.75,0.80,0.85,0.90$ and one specimen with $S$ equal to 1 . The cyclic load follows a sinusoidal wave with a frequency of $6 \mathrm{~Hz}$. The test was registered in terms of a complete cycle at each predetermined time interval. Parameters were chosen based on previous studies and on the literature $[23,32,37,46,47]$.

Specimens that reached 2,000,000 cycles, defined as endurance limit [28] (or in one case $1,000,000$ ), were, then, tested monotonically (deformation rate of $0.2 \mathrm{~mm} / \mathrm{min}$ ) until its complete failure (CMOD $>4.0 \mathrm{~mm}$ ). It was verified the maximum flexural load after the applied fatigue cycles $\left(\mathrm{P}_{\text {res,cycl }}\right)$. These specimens are named "run-out".

Fatigue life of HPFRC was evaluated in terms of total number of cycles until rupture of specimen $(\mathrm{N})$ for each $\mathrm{S}$. The progressive fatigue failure process and the evolution of cracks were recorded, as well as the crack opening at the upper load of first cycle $\left(\mathrm{CMOD}_{\mathrm{i}}\right)$, the crack opening of the last registered cycle $\left(\mathrm{CMOD}_{\mathrm{f}}\right)$ and the crack opening range $\left(\triangle \mathrm{CMOD}=\mathrm{CMOD}_{\mathrm{f}}\right.$ $-\mathrm{CMOD}_{\mathrm{i}}$ ). Figure 2 illustrates the loading pattern.

The adopted criterion of incrementing the individual load was an approach to observe the tendency in a S-N relationship. This criterion also evaluates each fatigue response whilst considering a homogeneous loading criterion for all tested beams and, therefore, reducing the scatter sources. For the analysis, all specimens were included. This decision was made on the fact that specimens were pre-crack and the $\mathrm{P}_{\text {upp }}$ was an individual representation of each case. Omitting "run-out" specimens would underestimate the real number of cycles up to failure. 


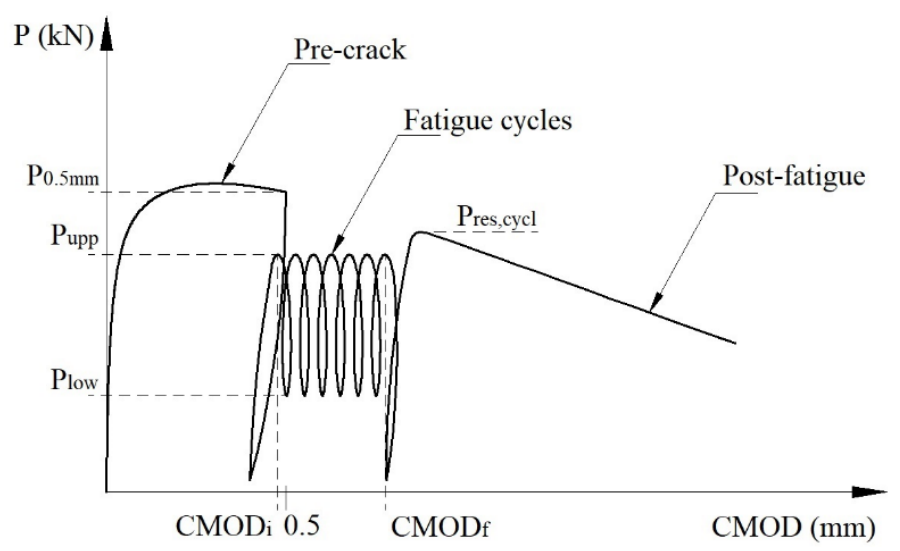

Figure 2 - Fatigue loading history (single column)

4. Results and discussion

\subsection{Mechanical characterization}

Average compressive strength and elastic modulus of HPRFC were 105.7 MPa (CV = $1.9 \%)$ and $44.0 \mathrm{GPa}(\mathrm{CV}=1.8 \%)$, respectively. Figure 3 shows the results from the flexural bending tests. It is presented the values of the mean residual flexural strengths $\left(f_{R, 1}, f_{R, 2}, f_{R, 3}\right.$, $\mathrm{f}_{\mathrm{R}, 4}$, corresponding to CMOD values of $0.5,1.5,2.5$ and $3.5 \mathrm{~mm}$, respectively) and the respective coefficient of variation (CV\%), according to Standard EN 14651:2005. The mean limit of proportionality ( $f_{\text {Lop }}$ ) was $19.65 \mathrm{MPa}(\mathrm{CV}=5.8 \%)$ and the maximum mean post-crack strength (MOR) was $29.62 \mathrm{MPa}(\mathrm{CV}=5.1 \%)$ at $\mathrm{CMOD}$ of $0.576 \mathrm{~mm}$. The MOR value represents an increment of about $50 \%$ of the $f_{\text {Lop }}$ value, showing that HPFRC has high ductility under flexure.

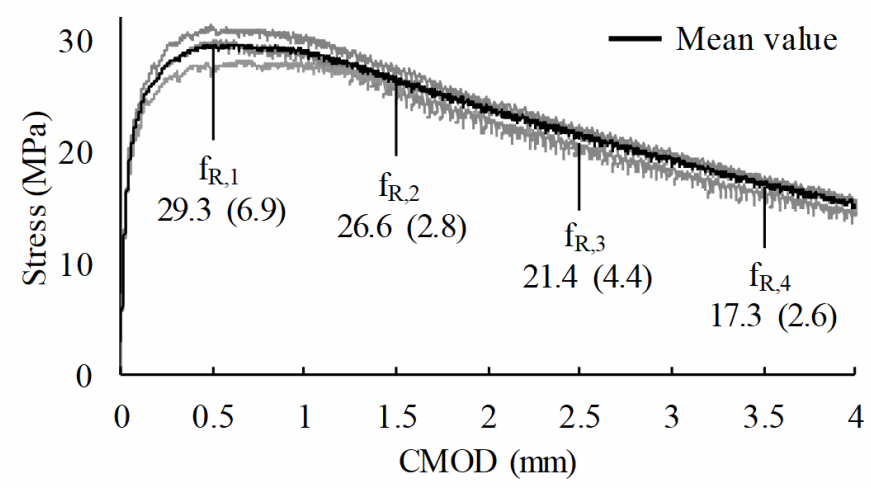

Figure 3 - Mean results from bending test on specimens and their respective coefficient of variability (single column)

The performance presented by HPFRC reveals a deflection-hardening behavior with high energy absorption capacity. After the first discontinuity of the static flexural strength curve, corresponding to the matrix crack, the fibers are activated and the strength increases, surpassing the cracking load. Additionally, several load drops can be identified on each curve. These represent fiber pull-out

\subsection{Fatigue test}

Table 3 summarizes the results of fatigue test on pre-cracked HPFRC specimen under bending. There were relevant differences when comparing numbers of cycle to failure of a series (same percentage of applied load). For $S$ of 0.70 , the difference of number of cycles to failure varied from 137,230 cycles to 2,000,000 cycles (run-out), and for $\mathrm{S}$ of $0.80, \mathrm{~N}$ varied 
from 238 to 32,569 cycles. This variation suggests that the fatigue life on pre-cracked specimens is a result of probabilistic difference in fiber orientation and distribution and a reflection of the fatigue scatter itself.

Table 3 - Results from fatigue tests on tested HPFRC specimens

\begin{tabular}{|c|c|c|c|c|c|c|}
\hline $\mathrm{S}\left(\% \mathrm{P}_{0.5 \mathrm{~mm}}\right)$ & $\mathrm{P}_{0.5 \mathrm{~mm}}(\mathrm{kN})$ & Cycles (N) & $\mathrm{CMOD}_{\mathrm{i}}(\mathrm{mm})$ & $\mathrm{CMOD}_{\mathrm{f}}(\mathrm{mm})$ & $\triangle \mathrm{CMOD}(\mathrm{mm})$ & $\mathrm{P}_{\text {res,cycl }}(\mathrm{kN})$ \\
\hline 0.65 & 20.41 & $2,000,000^{+}$ & 0.391 & 0.417 & 0.026 & 22.77 \\
\hline 0.65 & 17.71 & $2,000,000^{+}$ & 0.402 & 0.495 & 0.093 & 18.45 \\
\hline 0.65 & 17.50 & $2,000,000^{+}$ & 0.432 & 0.536 & 0.104 & 17.27 \\
\hline 0.70 & 15.45 & 137,230 & 0.448 & 1.409 & 0.960 & - \\
\hline 0.70 & 15.88 & $1,000,000^{+}$ & - & - & - & 16.45 \\
\hline 0.70 & 16.33 & $1,581,049$ & 0.432 & 1.804 & 1.372 & - \\
\hline 0.70 & 13.06 & $2,000,000^{+}$ & 0.429 & 0.663 & 0.234 & 13.46 \\
\hline 0.75 & 18.23 & 3,888 & 0.406 & 1.699 & 1.293 & - \\
\hline 0.75 & 17.75 & 4,821 & 0.417 & 2.723 & 2.306 & - \\
\hline 0.75 & 15.40 & 25,821 & 0.426 & 1.620 & 1.194 & - \\
\hline 0.80 & 15.88 & 238 & 0.450 & 5.607 & 5.158 & - \\
\hline 0.80 & 16.03 & 421 & 0.461 & 3.632 & 3.171 & - \\
\hline 0.80 & 14.64 & 1,103 & 0.441 & - & - & - \\
\hline 0.80 & 17.60 & 32,569 & 0.431 & 5.398 & 4.967 & - \\
\hline 0.85 & 13.96 & 176 & 0.473 & 3.193 & 2.719 & - \\
\hline 0.85 & 14.77 & 380 & 0.468 & 4.494 & 4.026 & - \\
\hline 0.85 & 14.78 & 448 & 0.473 & 3.497 & 3.024 & - \\
\hline 0.90 & 17.14 & 84 & 0.494 & 4.728 & 4.234 & - \\
\hline 0.90 & 16.08 & 86 & 0.496 & 4.455 & 3.959 & - \\
\hline 0.90 & 16.78 & 129 & 0.491 & 5.392 & 4.901 & - \\
\hline 1 & 16.87 & 49 & 0.549 & 5.334 & 4.785 & - \\
\hline
\end{tabular}

+ "Run-out"

\subsubsection{Cyclic creep curves}

Deformation evolution at the upper load level plotted as a function of the number of cycles is known as cyclic creep curve [27]. These curves can be classified into three stages, representing three phases of cracking. Phase I involves a large increase of deformation caused by preexisting microcracks. The secondary branch, or phase II, is characterized by a stable linear ascent and the slope denotes the crack increment per cycle (dCMOD/dn). Phase III is represented by the rapidly expand of the deformations at the end of the semi-stabilized curve until failure [43]. Figure 4 shows the average cyclic creep curves for each load level, in terms of normalized cycles (the ratio between the actual number of cycle $n$ and the number of cycles to failure $N$ ) versus the maximum CMOD $\left(\mathrm{CMOD}_{\text {upp }}\right)$ of each cycle. Since all specimens were pre-cracked, only phase II and phase III can be observed. Although the cyclic creep curve for $\mathrm{S}$ of 0.65 is shown, all specimens reached 2,000,000 cycles and did not fail.

The evolution of CMOD is dependent on the applied load level: as the load level increases, the slope of the crack increment per cycle becomes steeper and the crack opening displacement grows as well. Considering the mean fatigue life for each $\mathrm{S}(1,179,570$ cycles $(S=0.70) ; 11,510$ cycles $(S=0.75) ; 8,583$ cycles $(S=0.80) ; 335$ cycles $(S=0.85) ; 100$ cycles $(S=0,90) ; 49$ cycles $(S=1))$, the slope of phase II becomes steeper with smaller fatigue life. This 
relation suggests that the $\mathrm{dCMOD} / \mathrm{dn}$ appears to be correlated to the N. Lowering the secondary crack increment rate, the fatigue life increases.

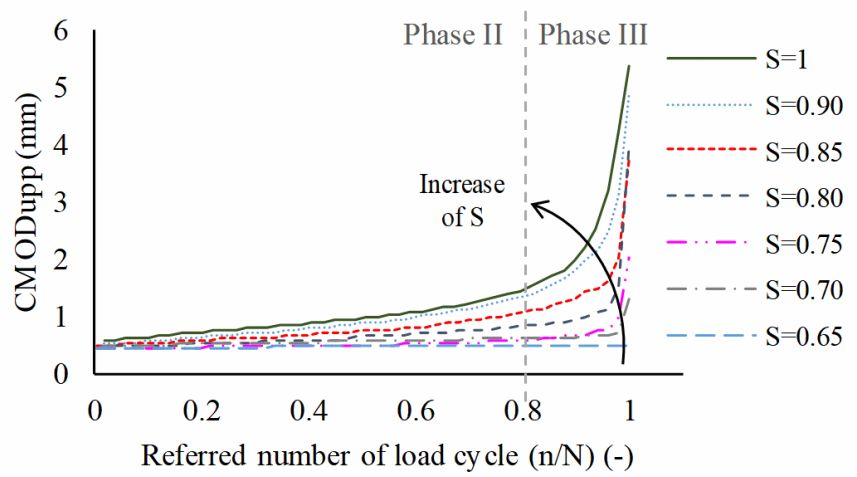

Figure 4 - Average cyclic creep curve for each load level (single column)

Figure 5 shows a comparison between $\triangle \mathrm{CMOD}$ and number of cycles to failure, highlighting the respective load level. Higher load levels show greater upper crack opening at the last cycle $\left(\mathrm{CMOD}_{\mathrm{f}}\right)$ and consequently crack opening range $(\triangle \mathrm{CMOD})$, than lower load cycles.

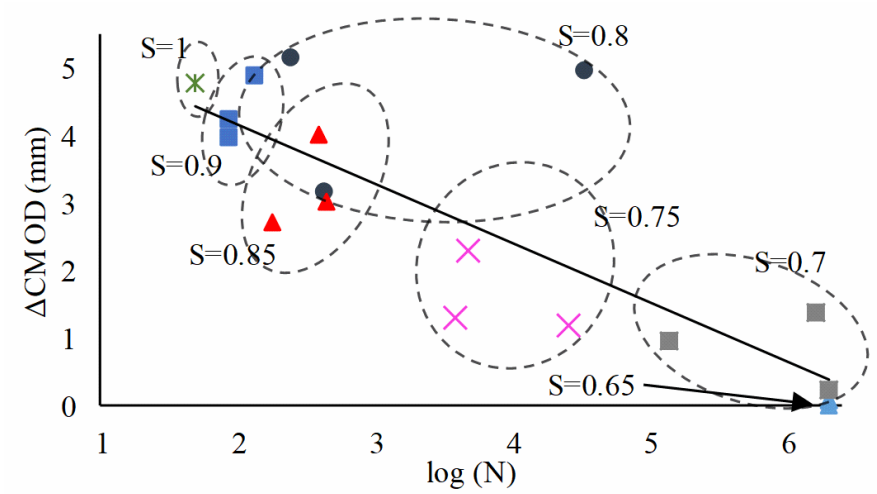

Figure 5 - Relation between crack opening range and number of cycles to failure (single column)

At higher S, the bend at phase III (Figure 4) displays smoother shape. Also, the failure

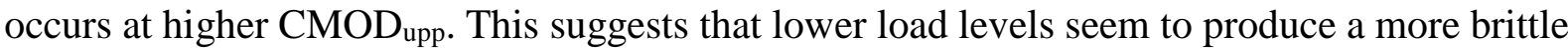
failure. This behavior was observed in fiber reinforced concrete in flexure by [48-51] and in UHPFRC by [32]. Higher S may failure through a continuous pull-out of the fibers, generating the ductile profile. Smaller load level can be responsible for the progressive weakening of the fiber-matrix interface through micro-cracks.

\subsubsection{Failure point under cyclic loading}

The concept of envelope curve provides a bound for the load and the crack opening values, establishing a failure criterion [12,21,27,46]. The envelope curve is generally approximated by the monotonic loading curve and it is schematically represented in Figure 6. Although most authors agree that the envelope curve concept is applicable for concrete subject to fatigue in compression, there is no agreement for fatigue in flexure or tension. 


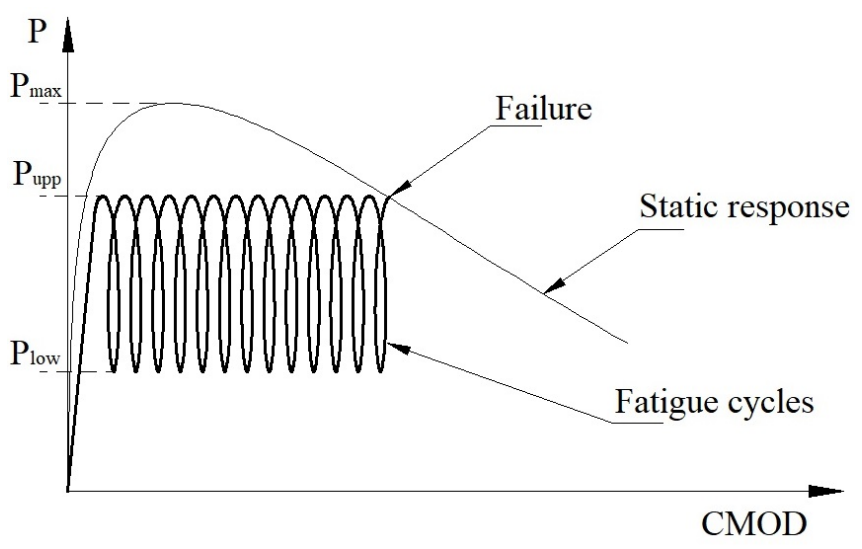

Figure 6 - Schematic representation of envelope curve in terms of applied load and CMOD (single column)

Throughout the fatigue loading test, the specimens could no longer reach the imposed load $\left(\mathrm{P}_{\text {upp }}\right)$, but the test did not stop until complete failure. This fact could have occurred because of the combined effect of high amount of fibers and the high frequency of the cycles. In order to associate the fatigue loading bearing capacity with the envelope curve, it was adopted as "fatigue limit of failure" a $2 \%$ loss of the reached load in a cycle when compared to $\mathrm{P}_{\text {upp. }}$. Figure 7 exhibits the normalized load, taking as reference $\mathrm{P}_{0.5 \mathrm{~mm}}$, vs the point where this loss is first detected $\left(\mathrm{CMOD}_{\mathrm{e}}\right)$ for each tested beam and a comparison to the static curve. It was also plotted a complete cyclic test of the specimen subjected to $S$ of 1 and fatigue life of 49 cycles to illustrate the gradual loss of stiffness. The mean relative vertical distance between the fatigue limit of failure points and the static curve for each $\mathrm{S}$ is emphasized.

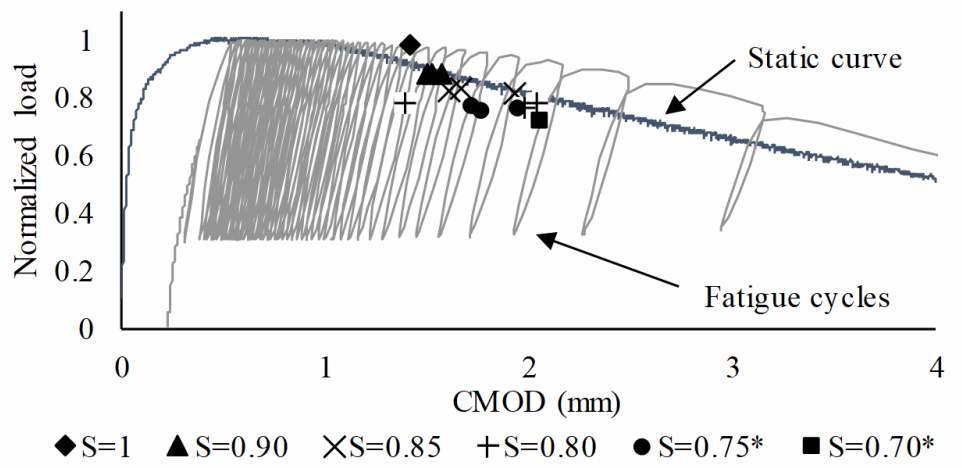

\begin{tabular}{cc}
\hline $\mathrm{S}$ & $\begin{array}{c}\text { Mean } \\
\text { vertical } \\
\text { difference }\end{array}$ \\
\hline $0.70^{*}$ & $-7.8 \%$ \\
\hline $0.75^{*}$ & $-8.7 \%$ \\
\hline 0.80 & $-7.4 \%$ \\
\hline 0.85 & $-3.7 \%$ \\
\hline 0.95 & $-1.8 \%$ \\
\hline 1 & $+6.4 \%$ \\
\hline
\end{tabular}

Figure 7 - Failure points of fatigue test, CMOD evolution, monotonic response in terms of normalized load and CMOD; and the mean vertical difference between the static curve and failure points (*stands for estimated points) (1.5 column)

The frequency that the fatigue-data of a test was registered was set considering the expected fatigue life of each specimen, due to data storage limitations. For this reason, the point where specimens tested at $S$ of 0.70 and 0.75 start to lose stiffness where estimated considering the trend observed in the graph with sufficient precision that the imposed load $\left(\mathrm{P}_{\text {upp }}\right)$ would be achieved.

Good agreement was found between the bearing capacity of specimens and the static curve, taking into account the typical dispersion. This shows that the envelope curve for the HPFRC can be approximated to the static monotonic curve. Considering the subsequent behavior, the continuous loss of stiffness in terms of evolution of CMOD, for the majority of the cases studied, seemed to proportionally respect the static curve.

Figure 8 illustrates a comparison between the cyclic creep curve and the correspondent CMOD vs load curve of the specimen subjected to $S$ of 0.90 and fatigue life of 129 cycles. 
Figure 8(b) shows the $\mathrm{CMOD}_{\text {upp }}$ vs load with switched axis to facilitate the interpretation of results.

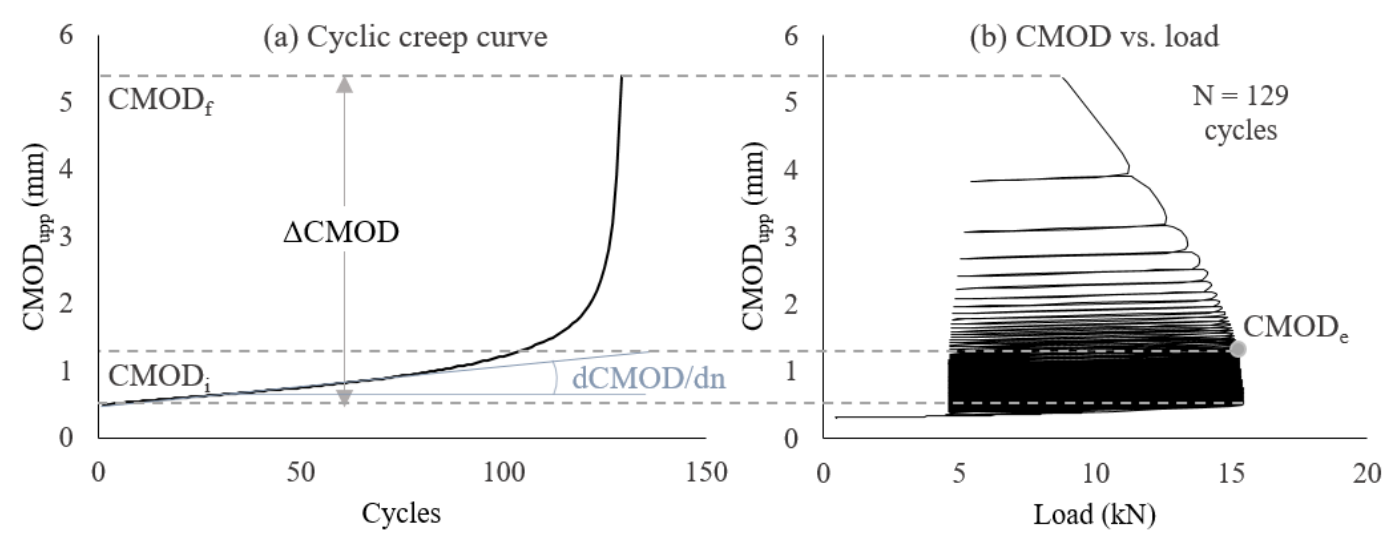

Figure 8 - Comparison between diagrams of cyclic creep curve (a) and CMOD vs load curve (b) (1.5 column)

Initially, the dCMOD/dn (slope of the CMOD-n relationship) is nearly constant and corresponds to the crack opening displacement ratio before reaching the envelope curve

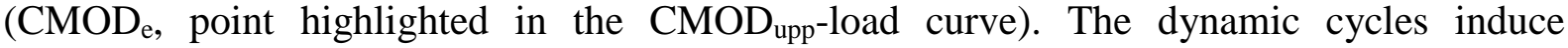
progressive damage in the cross section, causing growth of the CMOD and loss of load bearing capacity. Once the load reaches the envelope curve, the damage process is accelerated until failure $\left(\mathrm{CMOD}_{\mathrm{f}}\right)$. The load at failure is proportionally higher than the applied initial load regarding the distribution of the section

The envelope curve also suggests that the $\mathrm{CMOD}_{\mathrm{e}}$ depends predominantly on the upper load level $\left(\mathrm{P}_{\text {upp }}\right)$. The lower load level $\left(\mathrm{P}_{\text {low }}\right)$ dictates the amplitude $\left(\mathrm{P}_{\text {upp }}-\mathrm{P}_{\text {low }}\right)$, which is strongly related to the number of cycles to failure. Higher amplitude indicates a higher increment per cycle resulting in a smaller number of cycles to failure [9,52]. According to the results, the monotonic load-CMOD curves might be used as a deformation failure criterion for HPFRC under flexural fatigue loading. For a given $\mathrm{P}_{\text {upp }}$ and constant amplitude loading, the $\mathrm{CMOD}_{\mathrm{e}}$ can be predicted.

\subsubsection{Fatigue life}

The most common way to evaluate the fatigue behavior of concrete is the number of load cycle to failure. The results are shown by plotting the relative load level (S) versus the logarithm of the number of cycles to failure $(\mathrm{N})$. This curve is known as $\mathrm{S}-\mathrm{N}$ curve, or Wöhler curve and from that, it can be obtained the fatigue strength. Figure 9 shows the number of cycles to failure to each tested beam and the respective regression coefficient of determination $\left(\mathrm{R}^{2}\right)$.

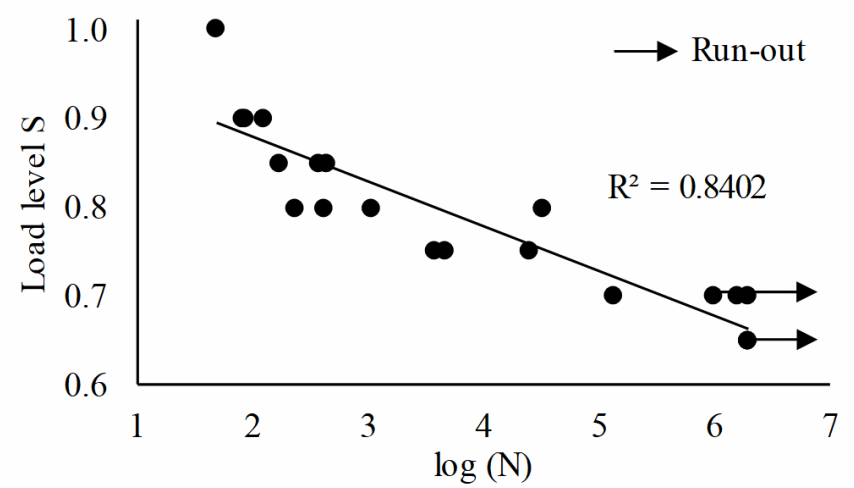

Figure 9 - Load level vs logarithm of cycles curve for HPFRC (single column) 
The corresponding $\mathrm{S}-\mathrm{N}$ equation which can be used for prediction purposes of precracked specimens of HPFRC considered within the experimental program is given by Eq.1.

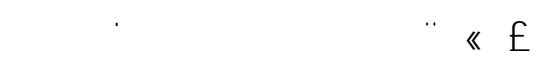

It is still not clear if concrete presents a fatigue limit, but it generally defined as maximum flexural fatigue load at which the beam can withstand 2,000,000 cycles of nonreversed fatigue loading $[28,31,40]$. Through the presented regression, HPFRC pre-cracked specimens seem to exhibit a fatigue endurance limit of 2,000,000 cycle of the order of 0.66 of $\mathrm{P}_{0.5 \mathrm{~mm}}$.

\subsubsection{Post-fatigue behavior}

The specimens that resisted the 2,000,000 cycles were monotonically tested to find the post-fatigue residual strength, respecting the same configurations of the flexural test. Considering the results presented in Table 3, Figure 10 shows the pre-crack loading, the first and the last cycle of the fatigue test, and the post-fatigue load for the four specimens that reached 2,000,000 cycles.

(a) $\mathrm{P}_{0.5 \mathrm{~mm}}=20.4 \mathrm{kN}, \mathrm{S}=0.65, \mathrm{P}_{\text {res,cycl }}=22.7 \mathrm{kN}$

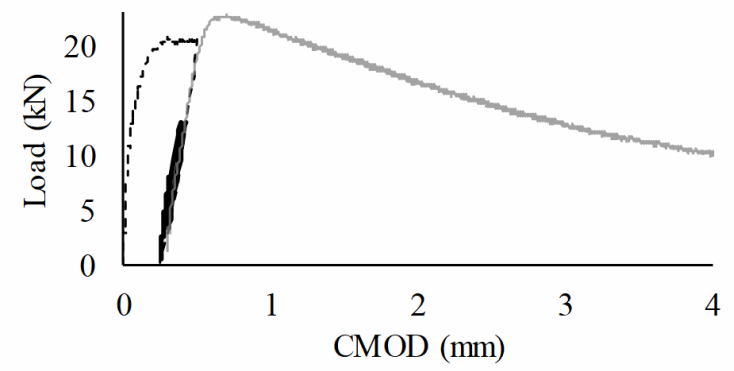

(c) $\mathrm{P}_{0.5 \mathrm{~mm}}=17.5 \mathrm{kN}, \mathrm{S}=0.65, \mathrm{P}_{\text {res,cycl }}=17.3 \mathrm{kN}$

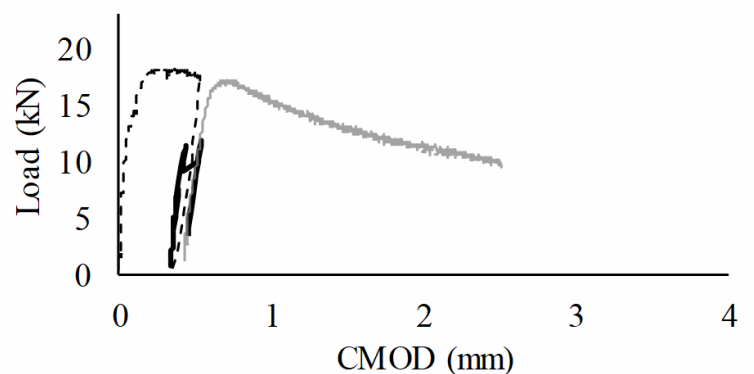

(b) $\mathrm{P}_{0.5 \mathrm{~mm}}=17.7 \mathrm{kN}, \mathrm{S}=0.65, \mathrm{P}_{\text {res,cycl }}=18.5 \mathrm{kN}$

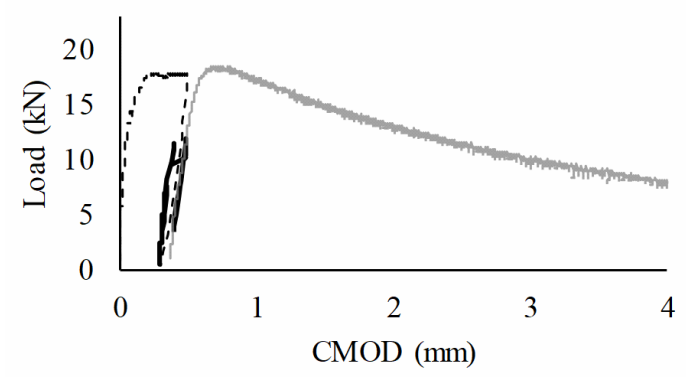

(d) $\mathrm{P}_{0.5 \mathrm{~mm}}=13.1 \mathrm{kN}, \mathrm{S}=0.70, \mathrm{P}_{\text {res, cycl }}=13.5 \mathrm{kN}$

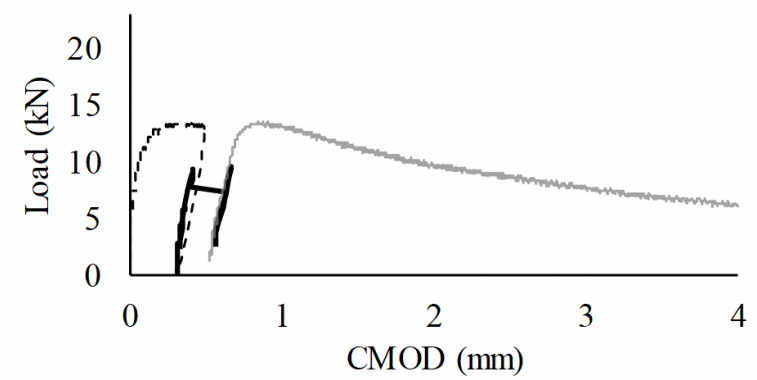

- - - Pre-crack Cyclic load Post-fatigue

Figure 10 - Post-fatigue behavior of run-out specimens (1.5 column)

Observing the overall behavior of the specimens, as cycles induce damage, they affect the crack opening, conducting to a displacement of the post-fatigue curve. However, the induced damage does not seem to affect the post-fatigue load bearing capacity, as the postfatigue curve tends to follow the shape expected for a static loading. In most of the cases, the maximum load of the post-fatigue peak $\left(\mathrm{P}_{\text {res,cycl }}\right)$ was higher than $\mathrm{P}_{0.5 \mathrm{~mm}}$ : the average value of

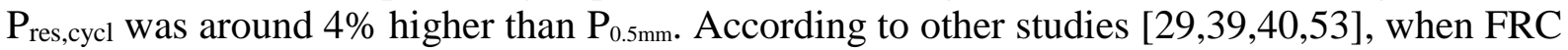
is subjected to a fatigue loading below the endurance limit value, there is an increase in the potential flexural strength.

It seems to have a correlation between the load at $\mathrm{P}_{0.5 \mathrm{~mm}}, \mathrm{CMOD}_{\mathrm{f}}$, and, consequently, $\triangle \mathrm{CMOD}$. Figure 10 (a), (b) and (c) shows samples subject to the same load level (0.65). 
Specimens with higher strength $\left(\mathrm{P}_{0.5 \mathrm{~mm}}\right)$ show smaller crack opening range ( $\left.\triangle \mathrm{CMOD}\right)$. The beam subjected to $S$ of 0.70 (Figure 10 (d)) appears to follow this assumption.

After the failure, the cross section of specimens subjected to different $\mathrm{S}$ were examined with 80-times magnifying glass (Figure 11). In all cases, steel microfiber did not break (Figure 11(b)). It suggests that fatigue failure of HPFRC occurs through a continuous fiber pull-out (Figure 11(c)) rather than a fatigue failure of the fibers due to their high-strength $(3,000$ $\mathrm{N} / \mathrm{mm}^{2}$ ). Therefore, the fatigue failure is attributable to damage at the matrix-fiber contact interface that progressively reduces the anchorage capacity.

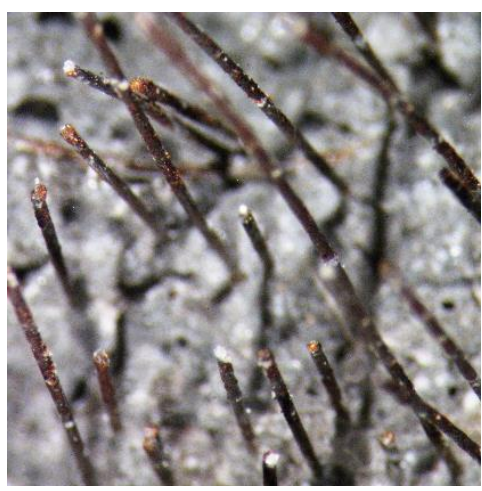

(a)

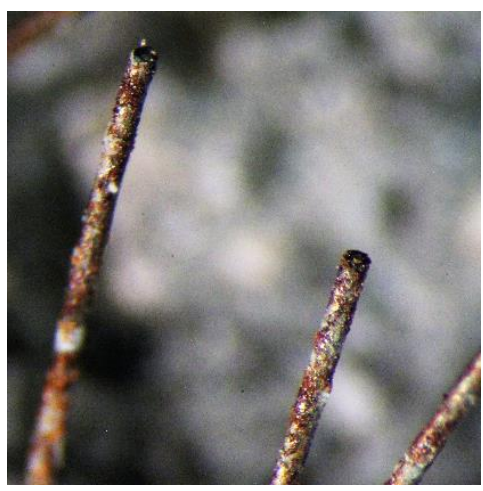

(b)

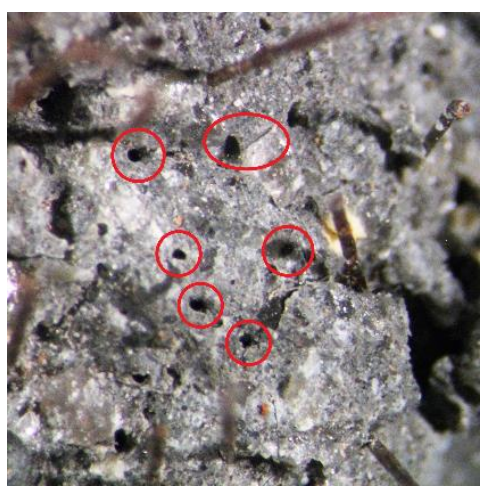

(c)

Figure 11 - Steel microfibers in the cementitious matrix: (a) cross section of failure; (b) fiber profile; (c) identification of cavities of fiber pull-out (1.5 column)

\subsection{Probabilistic approach}

Fatigue test data are normally presented as $\mathrm{S}-\mathrm{N}$ curves. The need of guaranteeing the target structural reliability level fixed when considering the limit state safety format [54] in a substantial scatter system, requires a probabilistic approach to ensure a consistent prediction of fatigue life [55].

To estimate the probability of fatigue failure $\left(P_{f}\right)$ of the studied HPFRC, two different approaches were adopted. Frequently, the logarithmic-normal (lognormal) distribution function is employed because of the mathematical convenience. However, the hazard function of the lognormal distribution decreases with increasing life [56]. This violates the physical phenomenon of progressive deterioration of materials resulting from the fatigue process. Because of it, the Weibull distribution is utilized for the statistical description of fatigue data. The other approach used to describe the $\mathrm{S}-\mathrm{N}-P_{f}$ relationship is by the mathematical model proposed by McCall [57] and slightly modified by Singh et al. [33]. The McCall model was used successfully to predict the fatigue life of various types of concretes $[35,36,55,57,58]$. Lastly, the Wöhler curve is compared with the Weibull distribution and the McCall model.

\subsubsection{Weibull distribution}

The cumulative distribution function (C.D.F.) $F_{N}(n)$ for the Weibull probability law may be expressed according to Eq. (2).

$$
\left.\dagger_{i}\left(\epsilon_{)}\right) \kappa^{\mathrm{N}}, ?\left[\frac{\mathrm{t}_{\mathrm{t}}^{\mathrm{t}}}{\mathrm{T}}\right\rceil^{\mathrm{K}}\right\rfloor
$$

in which $n$ is the specific value of the random variable $\mathrm{N}$; $\alpha$ is shape parameter or Weibull slope; and $u$ is the scale parameter or characteristic life.

First, a graphical method was employed to verify if the fatigue-life data of HPFRC can be modeled by the two-parameter Weibull distribution. Subsequently, three different methods 
were used to estimate the parameters of the distribution, $\alpha$ and $u$. These methods are the graphical method, method of moments and method of maximum likelihood.

Graphical method of analysis

Eq. (3) express the survivorship function $L_{N}(n)$ of the two-parameter Weibull distribution $[44,59,60]$.

$$
\text { ○ i (ढ़) }
$$

Taking the logarithm twice on both sides of Eq. (3), gives Eq. (4).

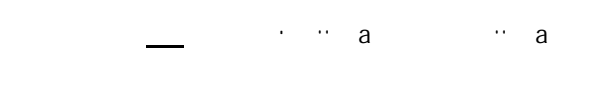

Eq. (4) represents a linear relationship between $\ln \left[\ln \left(1 / L_{N}\right)\right]$ and $\ln (N)$. To obtain a graph from Eq. (4), the fatigue-life data corresponding to each load level $\mathrm{S}$ was arranged in ascending order of cycles to failure. The empirical survivorship function $L_{N}$ for each fatigue-life data is obtained from Eq. (5).

$$
\checkmark \mathrm{i}-\kappa^{\mathrm{N}} \frac{\mathrm{OH}}{\mathrm{Sp}_{\mathrm{m}} \mathrm{r}}
$$

where $i$ denotes the failure order number and $k$ represents the number of data points.

There was a large variability in the fatigue-life data at the studied load levels and no definite trend was observed, indicating that the load levels selected for testing were probably too close together [61]. This inconveniency was mitigated by using the average value of the load levels 0.75 and $0.80(0.779)$ and 0.90 and 1 (0.925). Figure 12 shows the plotted relationship. The approximate straight-line plot indicates that the two-parameter Weibull distribution is a reasonable assumption for the statistical distribution of fatigue life of HPFRC. The parameters $\alpha$ and $u$ for the load levels were estimated from the regression analysis. Results are presented in Table 4.

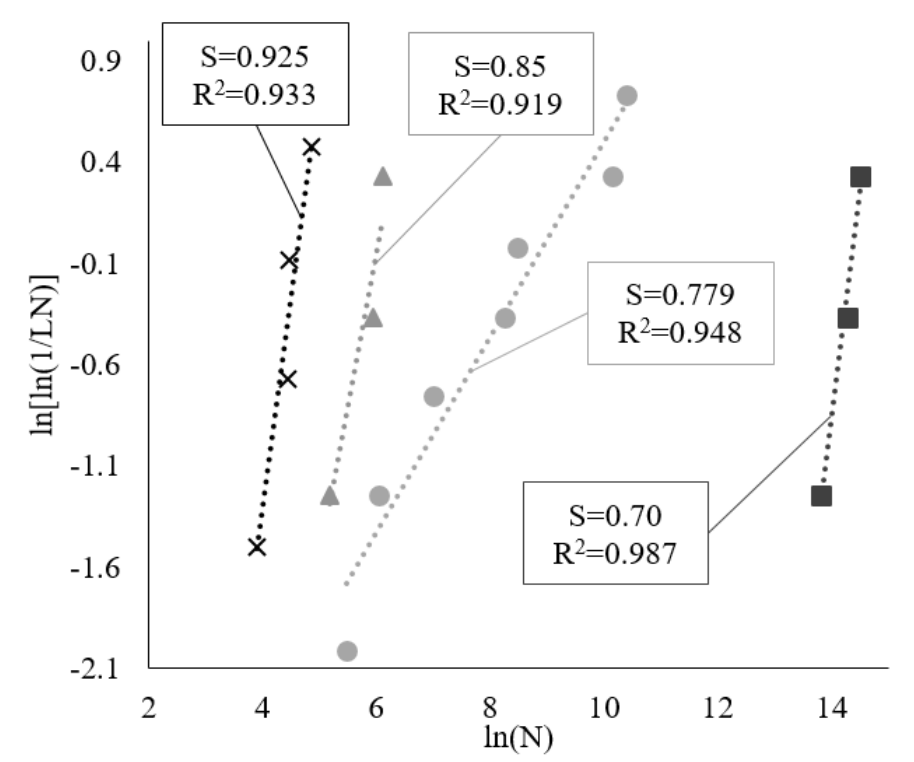

Figure 12 - Determination of coefficients of the fatigue equation (single column) 
$\underline{\text { Parameters from method of moments }}$

The estimation of parameters of the Weibull distribution by the method of moments requires sample moments, such as sample mean and sample variance. Eq. (6) and Eq. (7) were used to obtain the parameters $\alpha$ and $u$, respectively. Detailed calculations can be found in $[44,61]$.

$$
\begin{aligned}
& \text { ร. (सो) बथder. }
\end{aligned}
$$

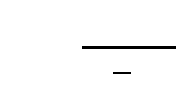

where mis the sample mean of the fatigue-life data at a given load level; CV $(=\mathrm{s} / \mathrm{m}$, $\mathrm{S}$ is standard deviation of sample) is the coefficient of variation of the data. Results are presented in Table 4.

$\underline{\text { Parameters from method of maximum likelihood estimate }}$

The probability density function of the Weibull distribution is given by Eq. (8).

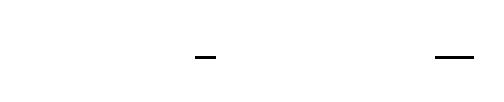

where ठ__ $।^{\mathrm{K}}$. Eq. (9) and Eq. (10) express the maximum likelihood equations $[44,59,60]$.

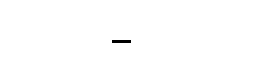

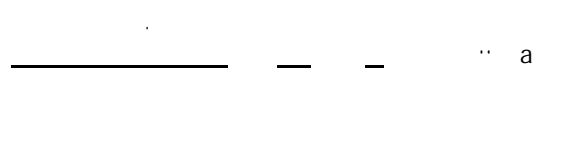

where $\alpha^{*}$ and $\theta^{*}$ are the maximum likelihood estimates of $\alpha$ and $\theta$, respectively. The parameter $\alpha$ was obtained from Eq. (10) by an iterative procedure. The values of $\alpha$ and $u$ are shown in Table 4 . The differences obtained within the preceding calculations may be due to the relatively few number of samples tested at each $\mathrm{S}$.

Table 4 - Parameters $\alpha$ and $\mathrm{u}$ for fatigue-life data of HPFRC for all calculation methods

\begin{tabular}{cccccc}
\hline $\begin{array}{c}\text { Load } \\
\text { level S }\end{array}$ & Parameter & Graphical method & Method of moments & $\begin{array}{c}\text { Maximum likelihood } \\
\text { estimate }\end{array}$ & Average \\
\hline \multirow{2}{*}{0.70} & $\alpha$ & 2.2209 & 3.3237 & 4.4104 & 3.3186 \\
\cline { 2 - 6 } & $u$ & $1,779,624.93$ & $1,701,716.77$ & $1,683,053.13$ & $1,721,473.90$ \\
\hline \multirow{2}{*}{0.779} & $\alpha$ & 0.4816 & 0.7117 & 0.6329 & 0.6088 \\
\cline { 2 - 6 } & $u$ & $7,830.17$ & $7,893.60$ & $7,010.31$ & $7,578.15$ \\
\hline \multirow{2}{*}{0.85} & $\alpha$ & 1.5144 & 2.5327 & 3.4926 & 2.5139 \\
\hline \multirow{2}{*}{0.925} & $\alpha$ & 412.21 & 377.06 & 374.27 & 387.86 \\
\cline { 2 - 6 } & $\alpha$ & 2.054 & 2.8723 & 3.3978 & 2.7751 \\
\hline
\end{tabular}

\section{Goodness-of-fit test}

The Kolmogorov-Smirnov test was applied as goodness-of-fit to the fatigue-life data at each load level. It is given by Eq. (11). 


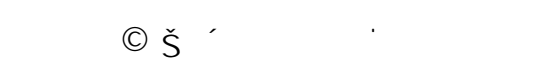

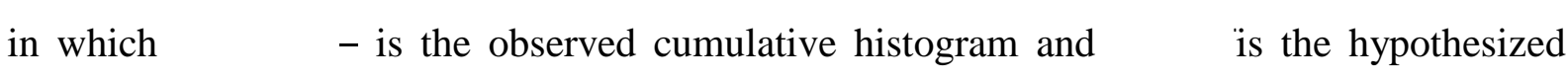
cumulative distribution function given by Eq. (2). The critical value $D_{c}$ is taken from the Kolmogorov-Smirnov table for a 5\% significance level. As $D_{c}>D_{n}$ (Table 5), the present model is accepted.

Table 5 - Kolmogorov-Smirnov test

\begin{tabular}{ccc}
\hline Load level & $\mathrm{D}_{\mathrm{n}}=\max \left|\mathrm{F}^{*}-\mathrm{F}_{\mathrm{N}}\right|$ & Critical value $\mathrm{D}_{\mathrm{c}}$ \\
\hline 0.70 & 0.1983 & 0.7076 \\
\hline 0.779 & 0.3269 & 0.4834 \\
\hline 0.85 & 0.2239 & 0.7076 \\
\hline 0.925 & 0.2608 & 0.6239 \\
\hline
\end{tabular}

\section{Flexural fatigue performance of HPFRC}

Load level 0.779 reveled $\alpha<1.0$ (Table 4), which leads to a decreasing hazard function with number of cycles. Although the graphical method as well as the goodness-of-fit test show that the Weibull distribution is a valid model in this situation, it violates the expected fatigue behavior. For this reason, the value of $\alpha=1.0$ can assumed [61] and the value of $u$ recalculated to $9.837,29$. Figure 13 shows the HPFRC C.D.F. curve vs the cycles.

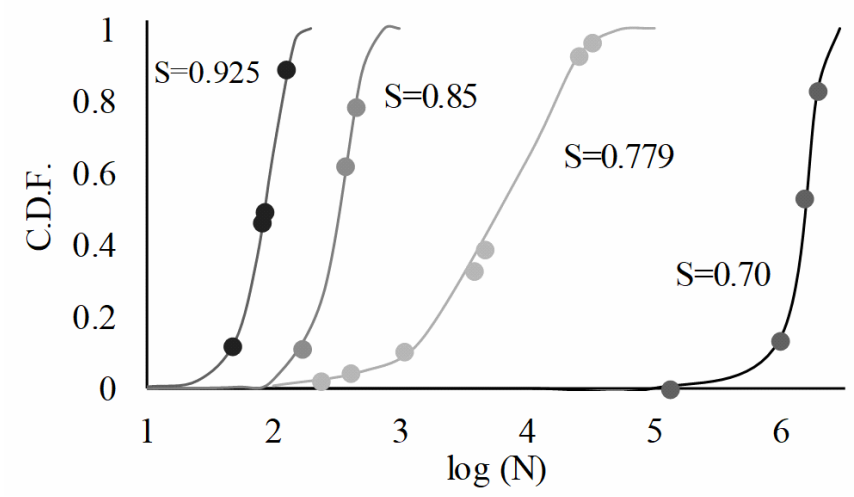

Figure 13 - Cumulated distribution function for HPFRC (single column)

Since the flexural fatigue-life data of HPFRC shows to follow the two-parameter Weibull distribution at different load levels, it can be used to calculate the fatigue lives corresponding to different failure probabilities $P_{f}$. Substituting $L_{N}=1-P_{f}$ and rearranging Eq. (4) gives Eq. (12).

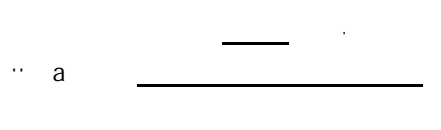

Using the mean values of the parameters of the Weibull distribution, Eq. (12) express the fatigue life $\mathrm{N}$ for a particular $P_{f}$. Figure 14 shows the fatigue life with a corresponding failure probability of $5 \%, 50 \%$ and $95 \%$. 


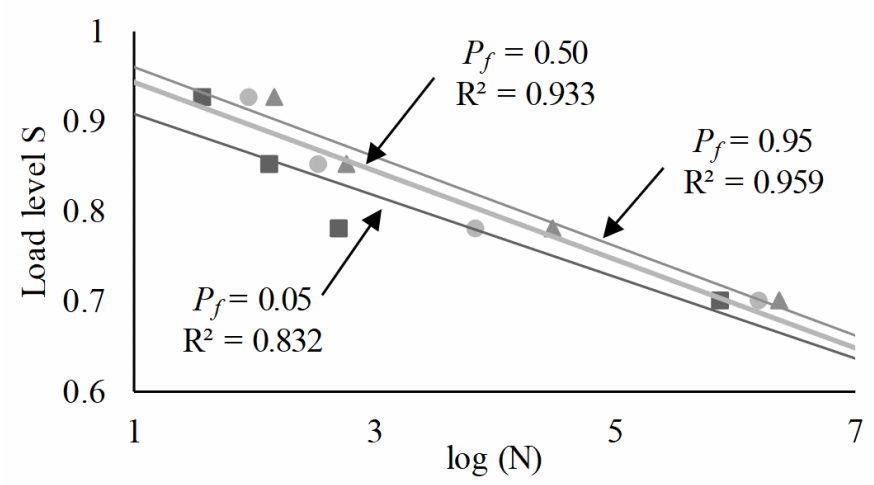

Figure 14 - Fatigue life of HPFRC calculated through the Weibull distribution (single column)

\subsubsection{Mathematical method: McCall model}

The McCall model [57] is based on a nonlinear relationship between S and logarithm of $\mathrm{N}$ given by Eq. (13).

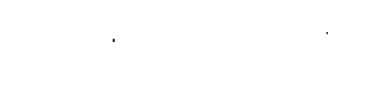

in which $\mathrm{L}=1-P_{f}$ is the survival probability; $a, b$ and $c$ are the experimental constants explained elsewhere [33].

The experimental data was ranked in an increasing order $(i)$ of cycle to failure at each load level. The probability of failure $\left(P_{f}\right)$ is calculated by dividing $i$ by $\left(1+\mathrm{n}_{\mathrm{s}}\right)$, where $\mathrm{n}_{\mathrm{s}}$ equals to the total number of specimens tested at each $\mathrm{S}$. Since all series of different $\mathrm{S}$ need to comprise the same number of specimens, Grubbs' test for outliers was used to discard additional samples. Specimens that survived 2,000,000 cycles were included in the analysis because generated logical S-N regression curves. The calculated values of probability of failure are shown in Table 6. The ratio $i /\left(1+\mathrm{n}_{\mathrm{s}}\right)$ is accepted to give best estimate of $P_{f}[33,55]$.

Table 6 - Fatigue-life data for HPFRC according to load level S and the respective probability of failure

\begin{tabular}{|c|c|c|c|c|c|c|c|}
\hline \multirow[b]{2}{*}{$i$} & \multicolumn{6}{|c|}{ Load level S } & \multirow{2}{*}{ 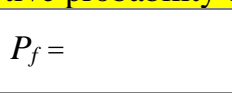 } \\
\hline & 0.65 & 0.70 & 0.75 & 0.80 & 0.85 & 0.90 & \\
\hline 1 & $2,000,000$ & 137,230 & 3,888 & 238 & 176 & 84 & 0.25 \\
\hline 2 & $2,000,000$ & $1,000,000$ & 4,821 & 421 & 380 & 86 & 0.50 \\
\hline 3 & $2,000,000$ & $1,581,049$ & 25,821 & 1,103 & 448 & 129 & 0.75 \\
\hline
\end{tabular}

A multiple linear regression analysis was performed in order to fit the experimental data with the analytical model, resulting in Eq. (14).

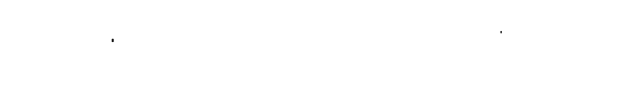

The $\mathrm{S}-\mathrm{N}-P_{f}$ curves for different values of $P_{f}$ are shown in Figure 15 and compared to the experimental data. Almost all of the experimental points fall between the curves for $P_{f}=$ $5 \%$ and $95 \%$. 


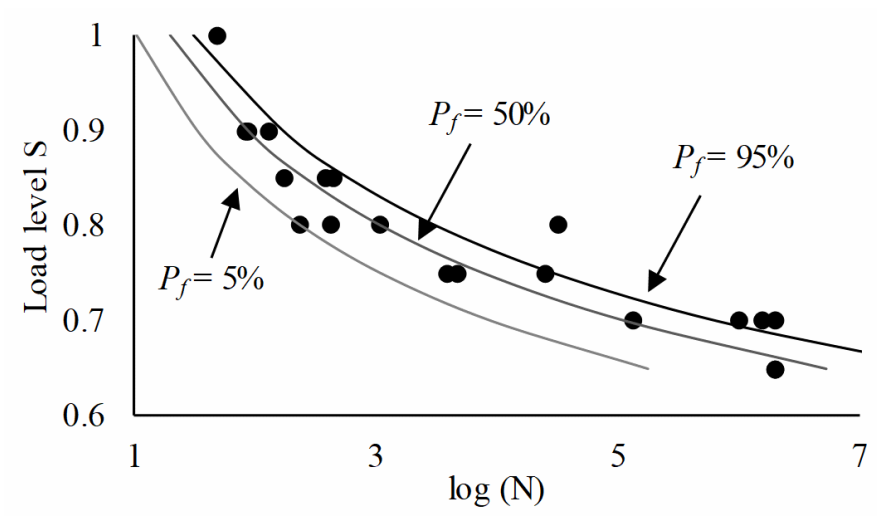

Figure $15-\mathrm{S}-\mathrm{N}$ curves considering various probabilities of failure (single column)

\subsubsection{Comparison between probabilistic methods}

To compare the investigates methods, the Wöhler curve considered the average values of $\mathrm{N}$, which corresponds to a $50 \%$ of fatigue life survival [55]. Similarly, both probabilistic approaches were calculated to a probability of failure of 50\%. Figure 16 shows the $\mathrm{S}-\mathrm{N}-P_{f}$ curves of Weibull distribution, McCall model, Wöhler curve and experimental data points and the respective calculated $R^{2}$.

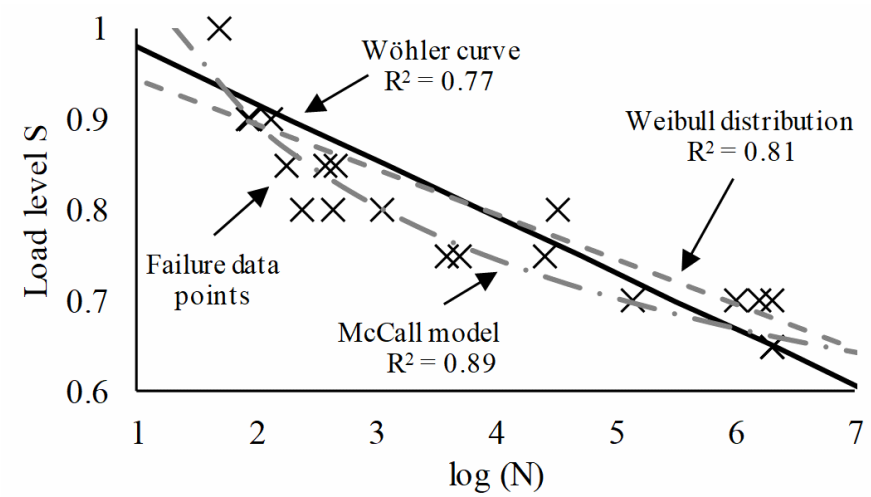

Figure 16 - Comparison between methods considering a probability of failure of $50 \%$ and the experimental data (single column)

Through the presented values of $\mathrm{R}^{2}$, the McCall model gives better prediction, followed by the curve given by the Weibull distribution. Even though the scope of this research presents low number of results for each load level, the mathematical method predicts reasonably well the flexural fatigue life of pre-cracked HPFRC for a desired probability of failure.

\section{Concluding remarks}

Post-cracking fatigue flexural strength of concrete subjected to flexural loading is an important design concern. Both experimental and theoretical studies were conducted on the flexural fatigue behavior of pre-cracked HPFRC specimens. The experimental program was carried out on monotonic and cyclic three-point bending notched beam tests. Seven load levels were applied with a constant amplitude ratio. The probabilistic approach has proven to be suitable to predict the fatigue of concrete. The main findings of this research are outlined below.

I Applied load level plays an important role on the CMOD development through cycles and the equivalent CMOD at failure. As the load level increases, the slope of the crack increment per cycle becomes steeper and the crack opening displacement grows as well. At higher $\mathrm{S}$, the bend at phase III displays smoother shape and the failure occurs at higher $\mathrm{CMOD}_{\text {upp. }}$ This suggests that lower load levels can cause a reduction of the 
ductility. Higher S may lead to failure through a continuous pull-out of the fibers, this generating a more ductile response. Smaller $\mathrm{S}$ can be responsible for the progressive weakening of the fiber-matrix interface through micro-cracks;

I Good agreement was found between the bearing capacity of specimens and the envelope curve. This result suggests that the monotonic load-CMOD curve might be used as failure criterion for HPFRC under flexural fatigue loading, at least for the adopted load levels $(\mathrm{S}=0.65,0.70,0.75,0.80,0.85,0.90,1)$ and frequency $(6 \mathrm{~Hz})$;

I The $\mathrm{S}-\mathrm{N}$ curve obtained allows affirming that HPFRC pre-cracked specimens have a fatigue endurance limit of 2,000,000 cycle of the order of $66 \%$ of $\mathrm{P}_{0.5 \mathrm{~mm}}$;

I Monotonic tests done on run-out specimens showed that the cyclic loads seem to act on the crack opening width, but not on the post-fatigue load capacity, regardless load level. In fact, in most of the cases, the maximum load of the post-fatigue peak was around 4\% higher than $\mathrm{P}_{0.5 \mathrm{~mm}}$. Such behavior confirms that the fatigue was done under the endurance limit;

I Looking into the cross section of specimens, it suggests that fatigue failure occurs due to damage at the matrix-fiber contact interface that progressively reduces the anchorage capacity. No damage on the steel microfiber was observed;

I The McCall mathematical method predicts reasonably well the flexural fatigue strength of pre-cracked HPFRC for a desired probability of failure.

The results obtained in this investigation are based on the small sized specimens. The high amount of fibers used in the investigated concrete responds to applications with relevant structural responsibility. For this reason, other studies considering variable and reversible loading patterns and scale effects should be carried out in order to ensure reliability for predictive capabilities with regard to structural applications.

\section{Acknowledgments}

The first author would like to thank the Brazilian National Council for Scientific and Technological Development for the scholarship granted (233980/2014-8). The development of this research has also been possible owe to the economic funds provided by the SAES project (BIA2016-78742-C2-1-R) of Spanish Ministerio de Economía, Industria y Competitividad. Likewise, this work has been possible thanks to the support provided by the Laboratory of Technology of Structures and Materials "Lluis Agulló" of Polytechnic University of Catalonia.

\section{References}

[1] A. de la Fuente, A. Blanco, J. Armengou, A. Aguado, Sustainability based-approach to determine the concrete type and reinforcement configuration of TBM tunnels linings. Case study: Extension line to Barcelona Airport T1, Tunn. Undergr. Sp. Technol. 61 (2017) 179-188. doi:10.1016/j.tust.2016.10.008.

[2] B. Belletti, R. Cerioni, A. Meda, G. Plizzari, Design aspects on steel fiber-reinforced concrete pavements, J. Mater. Civ. Eng. 20 (2008) 599-607. doi:Doi 10.1061/(Asce)0899-1561(2008)20:9(599).

[3] B. Graybeal, UHPC in the US Highway Infrastructure: experience and outlook, in: F. Toutlemonde, J. Resplendino (Eds.), RILEM-Fib-AFGC Int. Symp. Ultra-High Perform. Fibre-Reinforced Concr., Marseille, France, 2013: pp. 361-370.

[4] Y. Brugeaud, Express bridge deck and light duty bridge, in: F. Toutlemonde, J. Resplendino (Eds.), RILEM-Fib-AFGC Int. Symp. Ultra-High Perform. Fibre-Reinforced Concr., Marseille, France, 2013: pp. 389-394.

[5] S. Sritharan, G.M. Schmitz, Design of Tall Wind Turbine Towers Utilizing UHPC, in: F. Toutlemonde, J. Resplendino (Eds.), RILEM-Fib-AFGC Int. Symp. Ultra-High Perform. Fibre-Reinforced Concr., Marseille, France, 2013: pp. 433-442.

[6] N. Tapsoba, D. Citek, S. Dobrusky, J. Kolisko, Fatigue Behavior of Ultra-High Performance Concrete (UHPC) Under Compressive Loading, in: F. Toutlemonde, J. Resplendino (Eds.), HPFRC 2017 Des. Build. with UHPFRC New Large-Scale Implementations, Recent Tech. Adv. Exp. Stand., Montpellier, France, 2017: pp. 291-300. 
[7] K. Waagaard, Fatigue strength evaluation of offshore concrete structures, IABSE Proc. 6 (1982) 97-115.

[8] J.O. Holmen, Fatigue design evaluation of offshore concrete structures, Matériaux Constr. 17 (1984) 3942. doi:10.1007/BF02474054.

[9] F. Germano, G. Tiberti, G. Plizzari, Post-peak fatigue performance of steel fiber reinforced concrete under flexure, Mater. Struct. 49 (2016) 4229-4245. doi:10.1617/s11527-015-0783-3.

[10] D.Y. Yoo, N. Banthia, Mechanical and structural behaviors of ultra-high-performance fiber-reinforced concrete subjected to impact and blast, Constr. Build. Mater. 149 (2017) 416-431. doi:10.1016/j.conbuildmat.2017.05.136.

[11] E. Lappa, R. Braam, J. Walraven, Fatigue Failure Properties of High and Ultra High Strength Fibre Reinforced Concrete, in: G. Fischer, V.C. Li (Eds.), RILEM Proc. PRO 49 Int. RILEM Work. High Perform. Fiber Reinf. Cem. Compos. Struct. Appl., 2006: pp. 86-87.

[12] J. Zhang, H. Stang, V.C. Li, Fatigue life prediction of fiber reinforced concrete under flexural load, Int. J. Fatigue. 21 (1999) 1033-1049. doi:10.1016/S0142-1123(99)00093-6.

[13] N.K. Banjara, K. Ramanjaneyulu, Experimental Investigations and Numerical Simulations on the Flexural Fatigue Behavior of Plain and Fiber-Reinforced Concrete, J. Mater. Civ. Eng. 30 (2018) 04018151. doi:10.1061/(ASCE)MT.1943-5533.0002351.

[14] H.G. Russell, B.A. Graybeal, Ultra-High Performance Concrete: A State-of-the-Art Report for the Bridge Community, 2013.

[15] Japan Society of Civil Engineers, Recommendations for Design and Construction of High Performance Fiber Reinforced Cement Composites with Multiple Fine Cracks (HPFRCC), Concr. Eng. Ser. 82 (2008) Testing Method 6-10. http://www.jsce.or.jp/committee/concrete/e/index.html.

[16] Fib, International Federation for Structural Concrete fib Model Code for Concrete Structures 2010, Germany, 2013.

[17] DNV GL AS, Standard DNVGL-ST-0126 - Support structures for wind turbines, 2016.

[18] AFNOR, No TitleNF P18-710 Avril 2016 Complément national à l'Eurocode 2 - Calcul des structures en béton : règles spécifiques pour les bétons fibrés à ultra-hautes performances (BFUP), (2016).

[19] AFNOR, NF P 18-470 Juillet 2016 - Bétons - Bétons fibrés à ultra hautes performances - Spécification, performance, production et conformité, Paris, 2016.

[20] M. Schmidt, T. Leutbecher, S. Piotrowski, U. Wiens, The German Guideline for Ultra-High Performance, in: F. Toutlemonde, J. Resplendino (Eds.), UHPFRC 2017 Des. Build. with UHPFRC New Large-Scale Implementations, Recent Tech. Adv. Exp. Stand., Montpellier, France, 2017: pp. 545-554.

[21] P.B. Cachim, J.A. Figueiras, P.A.A. Pereira, Fatigue behavior of fiber-reinforced concrete in compression, Cem. Concr. Compos. 24 (2002) 211-217.

[22] A. Medeiros, X. Zhang, G. Ruiz, R.C. Yu, M.D.S.L. Velasco, Effect of the loading frequency on the compressive fatigue behavior of plain and fiber reinforced concrete, Int. J. Fatigue. 70 (2015) 342-350. doi:10.1016/j.ijfatigue.2014.08.005.

[23] B.T. Huang, Q.H. Li, S.L. Xu, W. Liu, H.T. Wang, Fatigue deformation behavior and fiber failure mechanism of ultra-high toughness cementitious composites in compression, Mater. Des. 157 (2018) 457468. doi:10.1016/j.matdes.2018.08.002.

[24] S. Cangiano, G.A. Plizzari, V. Slowik, Experimental investigation into the fatigue crack growth in concrete, in: Fract. Mech. Concr. Struct. Proc. Fram., 1996: pp. 645-654.

[25] T. Makita, E. Brühwiler, Tensile fatigue behaviour of ultra-high performance fibre reinforced concrete (UHPFRC), Mater. Struct. 47 (2014) 475-491. doi:10.1617/s11527-013-0073-x.

[26] J. Zhang, H. Stang, V.C. Li, Experimental Study on Crack Bridging in FRC under Uniaxial Fatigue Tension, J. Mater. Civ. Eng. 12 (2000) 66-73. doi:10.1061/(ASCE)0899-1561(2000)12:1(66).

[27] G.A. Plizzari, S. Cangiano, S. Alleruzzo, The fatigue behaviour of cracked concrete, Fatigue Fract. Eng. Mater. Struct. 20 (1997) 1195-1206. doi:10.1111/j.1460-2695.1997.tb00323.x.

[28] V. Ramakrishnan, G.Y. Wu, G. Hosalli, Flexural Fatigue Strength, Endurance Limit, and Impact Strength of Fiber Reinforced Concretes, Transp. Res. Rec. J. Transp. Res. Board. 1226 (1989) 17-24.

[29] E. Parant, P. Rossi, C. Boulay, Fatigue behavior of a multi-scale cement composite, Cem. Concr. Res. 37 (2007) 264-269. doi:10.1016/j.cemconres.2006.04.006.

[30] F.A. Farhat, D. Nicolaides, A. Kanellopoulos, B.L. Karihaloo, High performance fibre-reinforced cementitious composite (CARDIFRC) - Performance and application to retrofitting, Eng. Fract. Mech. 74 (2007) 151-167. doi:10.1016/j.engfracmech.2006.01.023.

[31] C.D. Johnston, R.W. Zemp, Flexural Fatigue Performance of Steel Fiber Reinforced Concrete--Influence of Fiber Content, Aspect Ratio, and Type, ACI Mater. J. 88 (1991) 374-383. doi:10.14359/1875.

[32] E.S. Lappa, High Strength Fibre Reinforced Concrete Static and fatigue behaviour in bending, Delft University of Technology, 2007. doi:978-90-9021935-6.

[33] S.P. Singh, B. Singh, S.K. Kaushik, Probability of fatigue failure of steel fibrous concrete, Mag. Concr. Res. 57 (2005) 65-72. doi:10.1680/macr.2005.57.2.65. 
[34] S.P. Singh, S.K. Kaushik, Fatigue strength of steel fibre reinforced concrete in flexure, Cem. Concr. Compos. 25 (2003) 779-786. doi:10.1016/S0958-9465(02)00102-6.

[35] S. Goel, S.P. Singh, P. Singh, Fatigue analysis of plain and fiber-reinforced self-consolidating concrete, ACI Mater. J. 109 (2012) 573-582.

[36] A.G. Graeff, K. Pilakoutas, K. Neocleous, M.V.N.N. Peres, Fatigue resistance and cracking mechanism of concrete pavements reinforced with recycled steel fibres recovered from post-consumer tyres, Eng. Struct. 45 (2012) 385-395. doi:10.1016/j.engstruct.2012.06.030.

[37] N. Ganesan, J. Bharati Raj, A.P. Shashikala, Flexural fatigue behavior of self compacting rubberized concrete, Constr. Build. Mater. 44 (2013) 7-14. doi:10.1016/j.conbuildmat.2013.02.077.

[38] A. Nanni, Fatigue behaviour of steel fiber reinforced concrete, Cem. Concr. Compos. 13 (1991) $239-245$. doi:10.1016/0958-9465(91)90029-H.

[39] G. Chanvillard, P. Pimienta, A. Pineaud, P. Rivillon, Fatigue flexural behaviour of pre-cracked specimens of Ductal ${ }^{\circ}$ UHPFRC, in: M. Di Prisco, R. Felicetti, G.A. Plizzari (Eds.), 6th Int. RILEM Symp. FibreReinforced Concr., 2004: p. 16.

[40] A.E. Naaman, H. Hammoud, Fatigue characteristics of high performance fiber-reinforced concrete, Cem. Concr. Compos. 20 (1998) 353-363. doi:10.1016/S0958-9465(98)00004-3.

[41] D.C. González, R. Moradillo, J. Mínguez, J.A. Martínez, M.A. Vicente, Postcracking residual strengths of fiber-reinforced high-performance concrete after cyclic loading, Struct. Concr. 19 (2018) 340-351. doi:10.1002/suco.201600102.

[42] S.H.P. Cavalaro, A. Aguado, Intrinsic scatter of FRC: an alternative philosophy to estimate characteristic values, Mater. Struct. 48 (2015) 3537-3555. doi:10.1617/s11527-014-0420-6.

[43] Fib, International Federation for Structural Concrete. Constitutive modelling of high strength/high performance concrete, Germany, 2008.

[44] B.H. Oh, Fatigue Analysis of Plain Concrete in Flexure, J. Struct. Eng. 112 (1986) $273-288$. doi:10.1061/(ASCE)0733-9445(1986)112:2(273).

[45] M. Tarifa, G. Ruiz, E. Poveda, X. Zhang, M.A. Vicente, D.C. González, Effect of uncertainty on load position in the fatigue life of steel-fiber reinforced concrete under compression, Mater. Struct. 51 (2018) 31. doi:10.1617/s11527-018-1155-6.

[46] J.-K. Kim, Y.-Y. Kim, Experimental study of the fatigue behavior of high strength concrete, Cem. Concr. Res. 26 (1996) 1513-1523. doi:10.1016/0008-8846(96)00151-2.

[47] S. Goel, S.P. Singh, P. Singh, Flexural fatigue strength and failure probability of Self Compacting Fibre Reinforced Concrete beams, Eng. Struct. 40 (2012) 131-140. doi:10.1016/j.engstruct.2012.02.035.

[48] P. SUTHIWARAPIRAK, T. MATSUMOTO, T. KANDA, Flexural fatigue failure characteristics of an engineered cementitious composite and polymer cement mortars., Doboku Gakkai Ronbunshu. 718 (2002) 121-134. doi:10.2208/jscej.2002.718_121.

[49] C.K.Y. Leung, Y.N. Cheung, J. Zhang, Fatigue enhancement of concrete beam with ECC layer, Cem. Concr. Res. 37 (2007) 743-750. doi:10.1016/j.cemconres.2007.01.015.

[50] S. Korte, V. Boel, W. De Corte, G. De Schutter, Static and fatigue fracture mechanics properties of selfcompacting concrete using three-point bending tests and wedge-splitting tests, Constr. Build. Mater. 57 (2014) 1-8. doi:10.1016/j.conbuildmat.2014.01.090.

[51] D. Li, P. Huang, X. Guo, X. Zheng, J. Lin, Z. Chen, Fatigue crack propagation behavior of RC beams strengthened with CFRP under cyclic bending loads, Fatigue Fract. Eng. Mater. Struct. 41 (2018) 212 222. doi:10.1111/ffe.12673.

[52] S. V. Kolluru, E.F. O’Neil, J.S. Popovics, S.P. Shah, Crack Propagation in Flexural Fatigue of Concrete, J. Eng. Mech. 126 (2000) 891-898. doi:10.1061/(ASCE)0733-9399(2000)126:9(891).

[53] V. Ramakrishnan, C. Mayer, A.E. Naaman, Cyclic behaviour, fatigue strength, endurance limit and models for fatigue behavior of FRC, Chapter. 4 (2014) 101-148.

[54] E. committee for Standardization, Eurocode - Basis of structural design - EN 1990:2002+A1 European Standards, 2008.

[55] M.-T. Do, O. Chaallal, P.-C. Aïtcin, Fatigue Behavior of High-Performance Concrete, J. Mater. Civ. Eng. 5 (1993) 96-111. doi:10.1061/(ASCE)0899-1561(1993)5:1(96).

[56] A.M. Freudenthal, E.J. Gumbel, On the Statistical Interpretation of Fatigue Tests, Proc. R. Soc. A Math. Phys. Eng. Sci. 216 (1953) 309-332. doi:10.1098/rspa.1953.0024.

[57] J.T. McCall, Probability of fatigue failure of plain concrete, J. Proc. 55 (1958) 233-244.

[58] S.P. Singh, Y. Mohammadi, S.K. Madan, Flexural fatigue strength of steel fibrous concrete containing mixed steel fibres, J. Zhejiang Univ. A. 7 (2006) 1329-1335. doi:10.1631/jzus.2006.A1329.

[59] S.P. Singh, S.K. Kaushik, Flexural Fatigue Analysis of Steel Fiber-Reinforced Concrete, ACI Mater. J. 98 (2001) 306-312.

[60] Y. Mohammadi, S.K. Kaushik, Flexural Fatigue-Life Distributions of Plain and Fibrous Concrete at Various Stress Levels, J. Mater. Civ. Eng. 17 (2005) 650-658. doi:10.1061/(ASCE)0899- 
1561(2005)17:6(650).

[61] S.P. Singh, S.K. Kaushik, Flexural Fatigue Life Distributions and Failure Probability of Steel Fibrous Concrete, ACI Mater. J. 97 (2000) 658-667. 